\title{
Queratitis de la interfase por cándida después de una queratoplastia lamelar anterior profunda tratada con queratoplastia penetrante temprana: reporte de un caso
}

\section{Candida interface keratitis after deep anterior lamellar keratoplasty treated with early penetrating keratoplasty: case report}

\author{
Ricardo Navarro-Saucedo ${ }^{1, *}$, Héctor G. Cámara-Castillo², César Hernández-Chavarría ${ }^{1}$ y \\ Juan J. Marx-Blanquer ${ }^{1}$ \\ ${ }^{1}$ Departamento de Oftalmología, Facultad de Medicina, Universidad Autónoma de Yucatán; ${ }^{2}$ Clínica de Mérida. Mérida, Yuc., México
}

\begin{abstract}
Resumen
Objetivo: Reportar un caso de queratitis de la interfase por cándida después de una queratoplastia lamelar anterior profunda (DALK) con lesiones pequeñas, tratada con queratoplastia penetrante temprana. Observaciones: Paciente de sexo masculino de 37 años tratado con DALK en el ojo derecho por queratocono. Pocos días después del procedimiento, el cultivo del rodete donador fue positivo para cándida. La profilaxis no evitó el desarrollo de la infección 3 meses después. Los antifúngicos tópicos y sistémicos no fueron efectivos. Aunque las lesiones eran pequeñas, se realizó queratoplastia penetrante (QPP). Los reportes microbiológico e histopatológico confirmaron queratitis de la interfase por Candida glabrata. A los 6 meses posquirúrgicos, la córnea permanece clara y la capacidad visual es de 20/30. Conclusiones e importancia del caso: Nuestro caso muestra que la QPP temprana, a pesar del pequeño tamaño de las lesiones, optimiza los resultados en la queratitis de la interfase por cándida después de DALK. Un cultivo de rodete donador positivo sirve para tomar la decisión oportuna.
\end{abstract}

Palabras clave: Cándida. Interfase. Fúngica. Queratitis. Queratoplastía lamelar anterior profunda.

\begin{abstract}
Objective: To report a case of interface keratitis caused by Candida after deep anterior lamellar keratoplasty (DALK) with small lesions, treated with early penetrating keratoplasty. Observations: The case is about a 37-year-old male treated with $D A L K$ on his right eye for keratoconus. Few days after the procedure, the donor rim culture was positive for Candida. Prophylaxis did not prevent the development of infection after three months. Topical and systemic antifungal therapy was not effective. Despite the small size of the lesions, we performed penetrating keratoplasty (PK). Microbiologic and histopathologic reports confirmed Candida glabrata interface keratitis. Six months after PK, the cornea remains clear with a best-corrected visual acuity of 20/30. Conclusions and importance of the case: Our case shows that early PK, despite the small size of the lesions, improves outcomes in Candida interface keratitis after DALK. A positive donor rim culture is useful for early decision making.
\end{abstract}

Key words: Candida. Interface. Fungal. Keratitis. Deep anterior lamellar keratoplasty.

Correspondencia:

${ }^{*}$ Ricardo Navarro-Saucedo

Calle 36 \#242A, dept.4, entre las calles 27 y 29

Col. García Ginerés

Fecha de recepción: 04-11-2019

Fecha de aceptación: 09-01-2020

E-mail: dr.ricardonavarro.s@gmail.com DOI: 10.24875/RMO.M20000127
Disponible en internet: 15-05-2020 Rev Mex Oftalmol. 2021:95(2):84-86 www.rmo.com.mx 0187-4519/๑ 2020 Sociedad Mexicana de Oftalmología. Publicado por Permanyer. Este es un artículo open access bajo la licencia CC BY-NC-ND (http://creativecommons.org/licenses/by-nc-nd/4.0/). 


\section{Introducción}

La Asociación Americana de Bancos de Ojos reporta una tasa de infecciones fúngicas (queratitis y endoftalmitis) después de una queratoplastia lamelar anterior del $0.52 \%$ en un periodo de 4 años. Las especies de cándida son los agentes más frecuentemente asociados con infección después de una queratoplastia lamelar anterior profunda (DALK) ${ }^{1}$. En áreas de alto riesgo de infecciones fúngicas, se recomienda realizar un cultivo del rodete donador debido a su alto valor predictivo positivo $(10.7 \%)^{2}$. Hay pocos casos de queratitis de la interfase por cándida después de DALK reportados ${ }^{3-9}$. Esta baja casuística dificulta la estandarización del tratamiento. Usualmente, se inicia de manera empírica tratamiento con antifúngicos tópicos y sistémicos en casos altamente sospechosos. La irrigación de la interfase con antifúngicos fue exitosa en un caso ${ }^{4}$, pero la mayoría de las veces se asocia a ruptura de la membrana de Descemet ${ }^{4-7}$. A continuación, reportamos nuestra experiencia con un caso de queratitis de la interfase por cándida después de DALK. Se obtuvo el consentimiento informado para la publicación de los resultados.

\section{Presentación del caso}

Se trata de un paciente de sexo masculino de 37 años con queratocono, tratado con DALK del ojo derecho sin eventualidades. A los 5 días del DALK, el cultivo del rodete donador resultó positivo para Candida glabrata, por lo tanto, iniciamos profilaxis con voriconazol tópico al $1 \% 4$ veces al día, así como fluconazol tabletas $400 \mathrm{mg}$ vía oral al día, inicialmente, y después, $200 \mathrm{mg}$ al día por 2 meses.

A los 3 meses de la queratoplastia, notamos dos infiltrados blancos en la interfase periférica donador-receptor, en el sector superior nasal, sin signos de inflamación. Entonces, reiniciamos el esquema de antifúngicos. A los 15 días, el paciente se presentó con hiperemia de 3 días de evolución, edema estromal ++, pliegues en Descemet, persistencia de los mismos infiltrados corneales, y otros tres en la interfase profunda (Fig. 1), y celularidad 1+ en la cámara anterior.

No hubo respuesta al tratamiento con antifúngicos y las características clínicas eran similares a las de un rechazo estromal, por lo que se trató con esteroide tópico. La hiperemia y la inflamación mejoraron, pero todos los infiltrados persistieron. La tomografía de coherencia óptica (OCT) del segmento anterior confirmó la ubicación de las lesiones en la interfase profunda (Fig. 2). El antecedente del cultivo del rodete donador positivo, la sospecha clínica por las características de

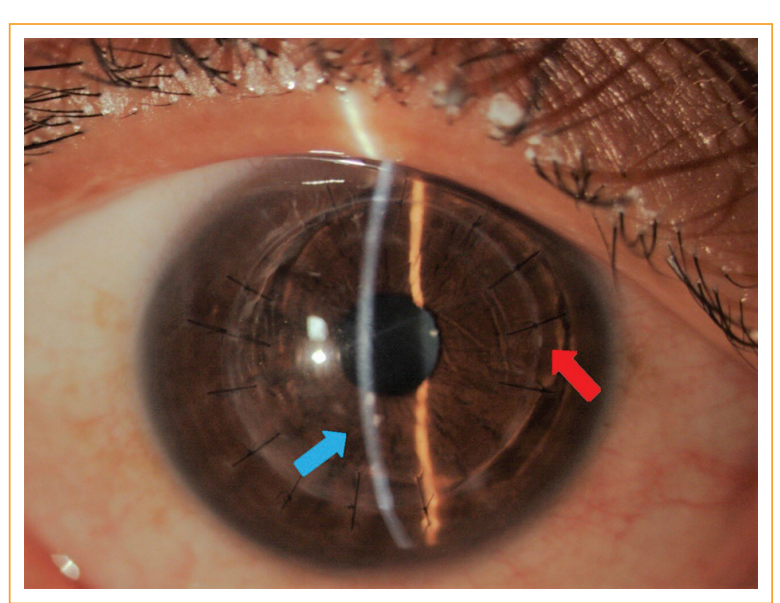

Figura 1. Fotografía de lámpara de hendidura de infiltrados blancos paracentrales en la interfase donador-receptor profunda (flecha azul) y periférica (flecha roja), justo antes de la queratoplastia penetrante.

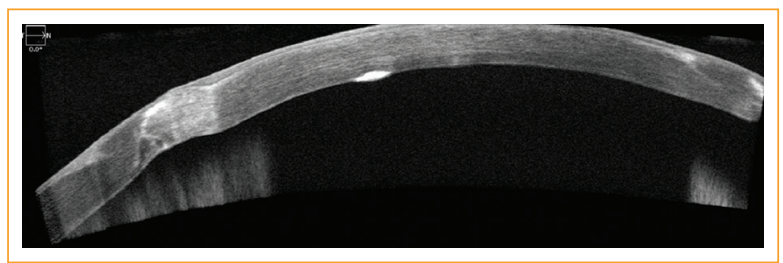

Figura 2. Tomografía de coherencia óptica del segmento anterior de alta definición que muestra una lesión hiperrefléctica entre la membrana de Descemet y el estroma corneal profundo.

los infiltrados, apoyado con la imagen del OCT de segmento anterior, y el mal pronóstico que podía asociarse si la infección progresaba nos condujeron a realizar una QPP con trépano de $8.25 \mathrm{~mm}(0.5 \mathrm{~mm}$ más grande que el trépano usado para el DALK). Enviamos el botón retirado a cultivo y estudio histopatológico (Fig. 3), y se confirmó el diagnóstico de queratitis por Candida glabrata, que coincide con el cultivo inicial.

A los 6 meses de la cirugía, el botón corneal permanece claro, sin recurrencia de la infección, y la capacidad visual es de 20/30 con dos suturas remanentes.

\section{Discusión}

Hay evidencia de que la profilaxis con antimicóticos en casos de un cultivo de rodete donador positivo para hongos puede reducir la incidencia de queratitis después de una queratoplastia ${ }^{10}$. En nuestro caso, no previno el desarrollo de la infección, pero contar con el resultado del cultivo fue esencial para tomar la decisión oportuna de realizar QPP. 


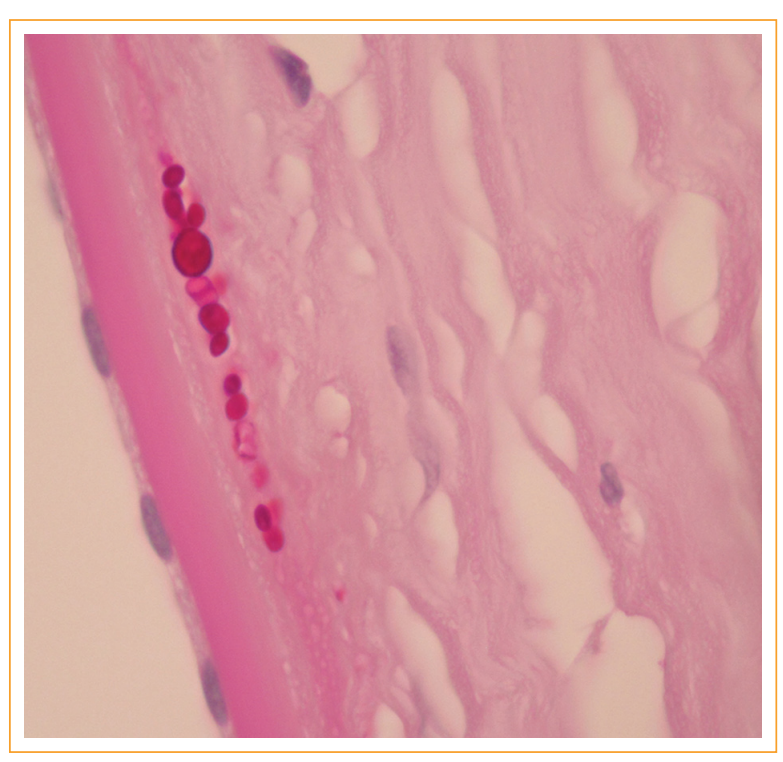

Figura 3. Fotomicrografías de estructuras levaduriformes PAS positivas en la interfase profunda adyacente a la membrana de Descemet, con una magnificación de 100X. PAS: ácido peryódico de Schiff.

El tiempo de inicio de una queratitis de la interfase por cándida después de DALK es de 4 días a 4 meses $^{9}$. En nuestro caso, la infección clínica se inició a los 3 meses.

El tratamiento con solo antifúngicos tópicos y sistémicos no ha sido efectivo en los casos reportados de queratitis de la interfase por cándida después de DALK $^{6,7}$, incluido el nuestro. La localización de la infección en la profundidad de la córnea podría explicar la alta tasa de falla a este tratamiento.

Uno de los principales diagnósticos diferenciales de una queratitis de la interfase, tal como fue considerado en 5 casos previos ${ }^{3-5,8}$, es el crecimiento epitelial en la interfase. También lo consideramos cuando los primeros infiltrados sin inflamación aparecieron, pero, cuando se agregaron los primeros signos de inflamación, nuestro principal diagnóstico diferencial fue rechazo estromal. En ese momento tratamos a nuestro paciente con esteroide tópico debido a que no hubo respuesta inicialmente a los antifúngicos. Finalmente, regresamos a nuestra sospecha inicial de queratitis fúngica por una respuesta incompleta a los esteroides. El tratamiento definitivo para nuestro paciente fue QPP, al igual que en la mayoría de los otros casos reportados ${ }^{4-8}$. Decidimos no irrigar la interfase por la alta tasa de ruptura de la membrana de Descemet. En la revisión por Fontana, et al., la QPP fue el tratamiento más efectivo. Ellos recomiendan QPP en cualquier momento que aparezcan signos de esparcimiento a pesar de los antifúngicos ${ }^{9}$.

\section{Conclusiones}

Basado en nuestros resultados, un cultivo del rodete donador positivo para cándida puede justificar la QPP con trepanación expandida en etapas tempranas de la infección, cuando las lesiones aún son pequeñas. Este abordaje terapéutico parece alcanzar una resolución de la infección más rápida y optimiza resultados.

\section{Agradecimientos}

Al Dr. Abelardo Rodríguez-Reyes, Jefe del Servicio de Patología APEC, Hospital Dr. Luis Sánchez Bulnes, por el estudio histopatológico y las fotomicrografías.

\section{Responsabilidades éticas}

Protección de personas y animales. Los autores declaran que los procedimientos seguidos se conformaron a las normas éticas del comité de experimentación humana responsable y de acuerdo con la Asociación Médica Mundial y la Declaración de Helsinki.

Confidencialidad de los datos. Los autores declaran que han seguido los protocolos de su centro de trabajo sobre la publicación de datos de pacientes.

\section{Derecho a la privacidad y consentimiento informado.}

Los autores han obtenido el consentimiento informado de los pacientes y/o sujetos referidos en el artículo. Este documento obra en poder del autor de correspondencia.

\section{Bibliografía}

1. Aldave AJ, DeMatteo J, Glasser DB, Tu EY, lliakis B, Nordlund ML, et al. Report of the Eye Bank Association of America Medical Advisory Board Subcommittee on Fungal Infection After Corneal Transplantation. Cornea. 2013;32(2):149-54.

2. Kiatos E, Armstrong JJ, Hutnik CM, Tsioros SM, Malvankar-Mehta MS, Hodge WG. The value of corneoescleral rim culture in keratoplasty: a systematic review and cost-effectiveness analysis. Clinicoecon Outcomes Res. 2017;9:459-74.

3. Sedaghat MR, Hosseinpoor SS. Candida albicans interface infection after deep anterior lamellar keratoplasty. Indian J Ophthalmol. 2012; 60(4):328-30.

4. Bahadir AE, Boskurt TK, Kutan SA, Yanyali CA, Acar S. Candida interface keratitis following deep anterior lamellar keratoplasty. Int Ophthalmol. 2012;32:383-6.

5. Kanavi MR, Forountan AR, Kamel MR, Afsar N, Javadi MA. Candida interface keratitis after deep anterior lamellar keratoplasty: clinical, microbiologic, histopathologic, and confocal microscopic reports. Cornea. 2007;26(8):913-6.

6. Wessel JM, Bachmann BO, Meiller R, Kruse FE. Fungal interface keratitis by Candida orthopsilosis following deep anterior lamellar keratoplasty. BMJ case reports. Disponible en: https://casereports.bmj.com/content/2013/bcr2012-008361.citation-tools. Consultado el 21 de julio de 2019.

7. Fontana L, Parente G, Di Pede B, Tassinari G. Candida albicans Interface Infection After Deep Anterior Lamellar Keratoplasty. Cornea. 2007;26(7):883-5.

8. Le Q, Wu D, Li Y, Ji J, Cai R, Xu J. Early-onset Candida glabrata interface keratitis after deep anterior lamellar keratoplasty. Optom Vis Sci. 2015;92:e93-6.

9. Fontana L, Moramarco A, Mandarà E, Russello G, lovieno A. Interface infectious keratitis after anterior and posterior lamellar keratoplasty. Clinical features and treatment strategies. A review. Br J Ophthalmol. 2018;0:1-8.

10. Vislisel JM, Goins KM, Wagoner MD, Schmidt GA, Aldrich BT, Skeie JM, et al. Incidence and Outcomes of Positive Donor Corneoescleral Rim Fungal Cultures after Keratoplasty. Ophthalmology. 2017;124(1):36-42. 